\title{
Comparison of gyrB gene sequences, 16S rRNA gene sequences and DNA-DNA hybridization in the Bacillus subtilis group
}

Correspondence

Fwu-Ling Lee

fll@firdi.org.tw

\author{
Li-Ting Wang, ${ }^{1}$ Fwu-Ling Lee, ${ }^{1}$ Chun-Ju Tai ${ }^{1}$ and Hiroaki Kasai ${ }^{2}$
}

${ }^{1}$ Bioresource Collection and Research Center, Food Industry Research and Development Institute, PO Box 246, Hsinchu 30099, Taiwan

${ }^{2}$ Marine Biotechnology Institute, Heita, Kamaishi, Iwate, 026-0001, Japan

\begin{abstract}
The Bacillus subtilis group comprises eight closely related species that are indistinguishable from one another by $16 \mathrm{~S}$ rRNA gene sequence analysis. Therefore, the gyrB gene, which encodes the subunit $B$ protein of DNA gyrase, was selected as an alternative phylogenetic marker. To determine whether gyrB gene sequence analysis could be used for phylogenetic analysis and species identification of members of the $B$. subtilis group, the congruence of gyr $B$ grouping with both 16S rRNA gene sequencing and DNA-DNA hybridization data was evaluated.

Ranges of $g y r B$ nucleotide and translated amino acid sequence similarities among the eight type strains were 75.4-95.0\% and 88.5-99.2\%, respectively, whereas $16 \mathrm{~S}$ rRNA gene sequence similarities were $98.1-99.8 \%$. Results showed that $g y r B$ gene sequences provide higher resolution than $16 \mathrm{~S}$ rRNA gene sequences. The classification achieved by gyrB sequence analysis was in agreement with results obtained with DNA-DNA hybridization. It is concluded that the gyrB gene may be an efficient alternative target for identification and taxonomic analysis of members of the $B$. subtilis group.
\end{abstract}

Bacillus subtilis is a Gram-positive, spore-forming, fermentative, aerobic, rod-shaped bacterium. The Bacillus subtilis group contains the closely related taxa Bacillus subtilis subsp. subtilis (Smith et al., 1964; Nakamura et al., 1999), Bacillus licheniformis (Skerman et al., 1980), Bacillus amyloliquefaciens (Priest et al., 1987), Bacillus atrophaeus (Nakamura, 1989), Bacillus mojavensis (Roberts et al., 1994), Bacillus vallismortis (Roberts et al., 1996), Bacillus subtilis subsp. spizizenii (Nakamura et al., 1999) and Bacillus sonorensis (Palmisano et al., 2001). These taxa can be differentiated from one another by fatty acid composition analysis, restriction digest analysis and DNADNA hybridization analysis, but are quite difficult to differentiate by phenotypic characteristics (Roberts et al., 1994; Nakamura et al., 1999).

16S rRNA gene sequence analysis is the most commonly used method for identifying bacteria or for constructing bacterial phylogenetic relationships (Woese, 1987;

The GenBank/EMBL/DDBJ accession numbers for the gyrB gene sequences of 32 strains used in this study are D0309293-DQ309325 and those of the 16S rRNA gene sequences are D0993674Da993679, EF423592-EF423609 and EF433402-EF433411, as detailed in Supplementary Table S1.

Details of strains and sequence accession numbers and a table of DNADNA reassociation values and gyrB and 16S rRNA gene sequences similarities are available as supplementary material with the online version of this paper.
Vandamme et al., 1996; Joung \& Cote, 2002); however, its usefulness is limited because of the high percentage of sequence similarity between closely related species (Ash et al., 1991; Martínez-Murcia et al., 1992; Christensen et al., 1998). The use of protein-encoding genes as phylogenetic markers is now a common approach (Yamamoto \& Harayama, 1998; Ko et al., 2004; Chelo et al., 2007). Detailed investigations have demonstrated that sequences from protein-encoding genes can accurately predict genome relatedness and may replace DNA-DNA hybridization for species identification and delineation in the future (Stackebrandt et al., 2002; Zeigler, 2003).

The $g y r B$ gene encodes the subunit B protein of DNA gyrase, a type II DNA topoisomerase, which plays an essential role in DNA replication and is distributed universally among bacterial species (Watt \& Hickson, 1994; Huang, 1996). The rate of molecular evolution inferred from $\operatorname{gyr} B$ gene sequences is faster than that inferred from 16S rRNA gene sequences (Yamamoto \& Harayama, 1995). gyrB gene sequences have been used in phylogenetic studies of Pseudomonas (Yamamoto \& Harayama, 1998), Acinetobacter (Yamamoto \& Harayama, 1996; Yamamoto et al., 1999), Mycobacterium (Kasai et al., 2000; Niemann et al., 2000), Salmonella, Shigella and Escherichia coli (Fukushima et al., 2002), Aeromonas (Yáñez et al., 2003) and the Bacillus anthracis-cereus-thuringiensis group (La Duc et al., 2004); results from these studies have indicated that $\operatorname{gyr} B$ is a 
suitable phylogenetic marker for the study of phylogenetic and taxonomic relationships at the species level. In the present study, it has been shown that direct sequencing of the $\operatorname{gyr} B$ gene could be used for identification and phylogenetic analysis of species of the B. subtilis group.

A total of eight Bacillus type strains and 24 Bacillus reference strains were used in this study (see Supplementary Table S1 available in IJSEM Online). They were obtained from the Bioresource Collection and Research Center (BCRC; http://wdcm.nig.ac.jp/CCINFO/CCINFO.xml?59). All strains were cultivated on nutrient agar or in nutrient broth (Difco) at $30{ }^{\circ} \mathrm{C}$ for $24 \mathrm{~h}$ under aerobic conditions.

Genomic DNA was extracted using the Qiagen Blood \& Cell Culture DNA kit. DNA-DNA relatedness values were determined using the fluorometric hybridization method in microdilution wells as described previously (Ezaki et al., 1989; Chern et al., 2004; Tai et al., 2006).

The $\operatorname{gyrB}$ gene was amplified by PCR as described previously (Yamamoto \& Harayama, 1995). PCR was performed using the Takara Ex Taq kit. PCR products were purified with the PCR-M clean up system (Viogene) and sequenced with a BigDye Terminator v3.1 cycle-sequencing kit on a 3730 DNA sequencer (Applied Biosystems and Hitachi). DNA sequencing was determined using $\operatorname{gyrB}$ degenerate primers UP-1S and UP-2Sr (Yamamoto \& Harayama, 1995) and BS-F (5'-GAAGGCGGNACNCAYGAAG- $3^{\prime}$ ) and BS-R (5'-CTTCRTGNGTNCCGCCTTC-3') (designed from conserved regions of $g y r B$ nucleotide sequences of members of the B. subtilis group) at $3.2 \mu \mathrm{M}$ concentration. The DNA sequence was double-checked by sequencing both strands. Approximately $1.5 \mathrm{~kb}$ of the $16 \mathrm{~S}$ rRNA gene was determined using the MicroSeq Full Gene 16S rDNA Bacterial Identification kit (Applied Biosystems).

Sequence similarities were calculated using programs of the Wisconsin Package, version 10.1 (Accelrys). Multiple sequences were aligned using the program CLUSTAL_X, version 1.8 (Thompson et al., 1997). Phylogenetic analysis was performed using PHYLIP (Felsenstein, 1993) and MEGA (Kumar et al., 2004). Evolutionary distances were calculated by Kimura's two-parameter model (Kimura, 1980). Phylogenetic trees were constructed by the neighbour-joining (Saitou \& Nei, 1987) and maximum-parsimony (Fitch, 1971) methods with bootstrap values based on 1000 replications.

Approximately $1.2 \mathrm{~kb}$ of the gyrB gene was successfully amplified using universal primers UP-1 and UP-2r for all Bacillus species examined in this study. After direct sequencing, $1171 \mathrm{bp}$ gyrB gene sequences, corresponding to nt 316-1480 of the Escherichia coli K-12 sequence with gaps, and 1468 bp $16 \mathrm{~S}$ rRNA gene sequences, corresponding to nt 30-1489 of the E. coli K-12 sequence with gaps, were used for analysis and the resulting data were deposited in GenBank/EMBL/DDBJ. Accession numbers of gyrB and $16 \mathrm{~S}$ rRNA gene sequences are listed in Supplementary Table S1.

\section{Species identification and phylogenetic analysis of $B$. subtilis and related taxa based on gyrB gene sequence analysis}

The gyrB gene sequence similarities between the eight type strains were 75.4-95.0\% (mean 81.6\%) (see Supplementary Table S2). The gyrB translated amino acid sequence similarity values were $88.5-99.2 \%$ (mean $92.5 \%$ ) (data not shown). In contrast, $16 \mathrm{~S}$ rRNA gene sequence similarities between the same strains were 98.1-99.8\% (mean 98.9\%). It is clear from comparative sequence analysis that the base substitution rate of the $g y r B$ gene sequence was much faster than that of the 16S rRNA gene sequence and that the $\operatorname{gyrB}$ nucleotide sequence showed significantly higher genetic variation than the translated amino acid sequence.

The $\operatorname{gyr} B$ gene sequence showed remarkable discrimination (75.4-91.9\%). At the intraspecies level, the nucleotide substitution rates were $0-5 \%$ and were $<2 \%$ for most Bacillus species. At the interspecies level, the nucleotide substitution rates were usually $>7 \%$, except for B. vallismortis and B. subtilis subsp. spizizenii, the most similar pair (6.1\% sequence divergence). At the subspecies level, the gyrB gene sequence could be used to discriminate B. subtilis subsp. subtilis from B. subtilis subsp. spizizenii (5\% sequence divergence). This result was consistent with that of $g y r A$ gene sequence analysis ( $4.8 \%$ sequence divergence) (Chun \& Bae, 2000). The 16S rRNA gene sequences of all Bacillus strains tested revealed more than $98 \%$ similarity. These results indicate that the $\operatorname{gyrB}$ gene is more useful than the $16 \mathrm{~S}$ rRNA gene for species and subspecies identification in the B. subtilis group.

The phylogenetic trees constructed from the 16S rRNA and gyrB gene sequences of the 32 Bacillus strains are shown in Fig. 1. The gyrB-based tree clearly delineated four distinct clusters with high bootstrap values $(100 \%)$ : cluster 1 contained B. subtilis, B. vallismortis and B. mojavensis strains; clusters 2 and 3 contained strains of $B$. atrophaeus and $B$. amyloliquefaciens, respectively; and cluster 4 contained B. sonorensis and B. licheniformis strains (Fig. 1). Of the B. subtilis strains, all strains of $B$. subtilis subsp. subtilis formed a monophyletic clade with $100 \%$ bootstrap support; the $g y r B$ gene sequence similarities among them were $98.1-99.1 \%$ (mean $98.7 \%$ ) (data not shown) and the sequence divergence between the $B$. subtilis subsp. subtilis and B. subtilis subsp. spizizenii strains was $5.0 \%$. Comparatively, the 16S rRNA gene-based tree yielded two clusters with a bootstrap value of $79 \%$ : cluster 1 contained strains of $B$. subtilis, $B$. mojavensis, $B$. vallismortis, $B$. atrophaeus and B. amyloliquefaciens and cluster 2 contained strains of B. sonorensis and B. licheniformis. All Bacillus strains among these two cluster groups showed more than $99 \% 16 \mathrm{~S}$ rRNA gene sequence similarity, indicating that the $g y r B$ gene is a better molecular marker than the 16S rRNA gene for the study of phylogenetic and taxonomic relationships at the species level in the B. subtilis group. 
(a) $16 \mathrm{~S}$ rRNA

(b) $g y r B$

Species group

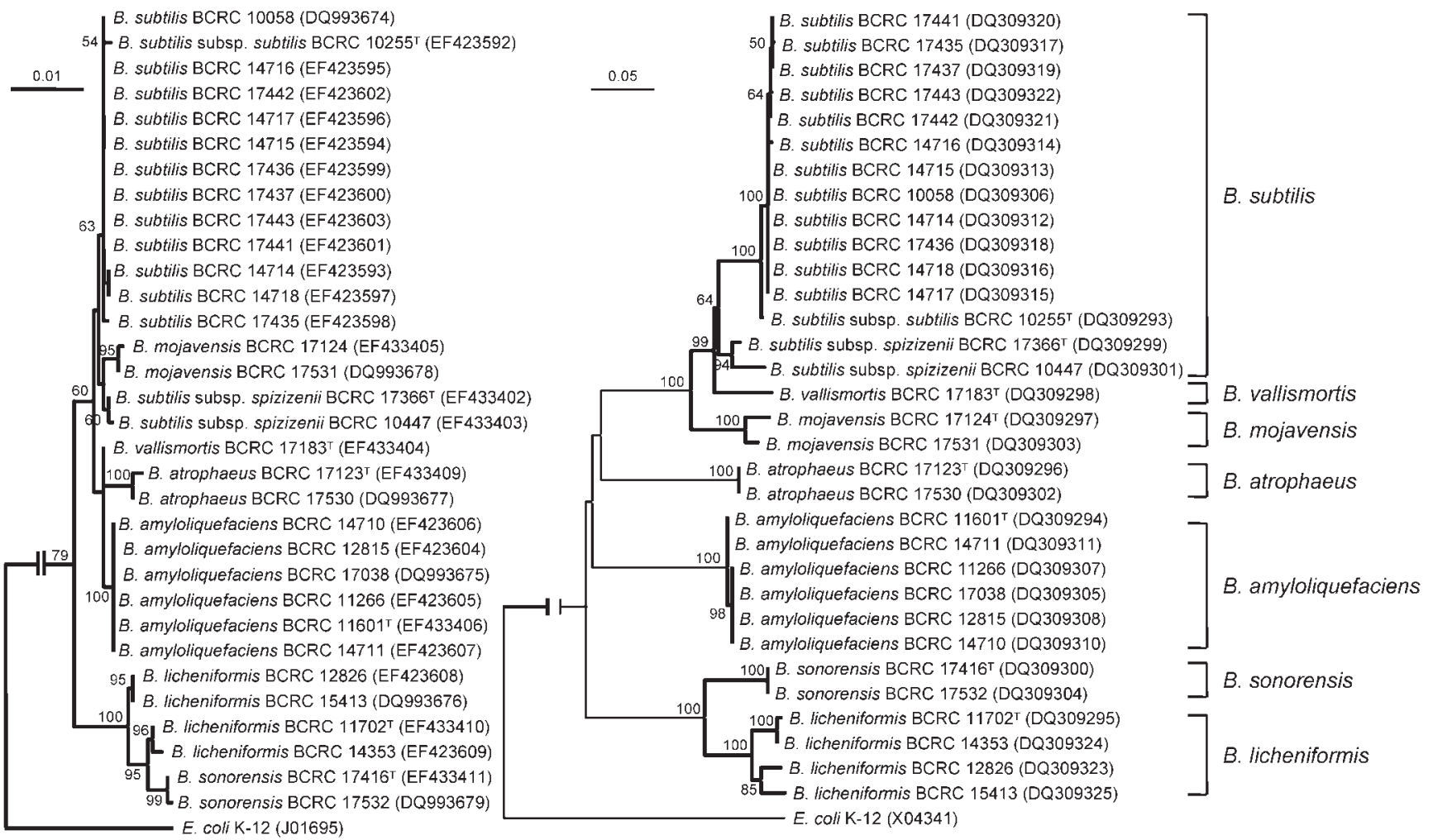

Fig. 1. Phylogenetic trees of 32 Bacillus strains based on $16 \mathrm{~S}$ rRNA (a) and gyrB (b) gene sequences. The trees were constructed with the neighbour-joining method. Genetic distances were computed by Kimura's two-parameter model. E. coli K-12 was included as an outgroup. Only bootstrap percentages above $50 \%$ are shown (based on 1000 replications). Bars, 0.01 (a) or 0.05 (b) substitutions per nucleotide position.

\section{Correlation between gyrB gene sequence similarity and DNA-DNA relatedness}

In the modern taxonomy of bacteria, direct genomic DNA-DNA hybridization comparisons have been deemed the 'gold standard' in bacterial characterization and identification (Wayne et al., 1987; Stackebrandt et al., 2002). Reassociation values obtained from DNA-DNA hybridization analyses among the type strains and other Bacillus strains examined in this study were determined (data not shown). The DNA-DNA reassociation values between the eight type strains were low, 11-67\% (Supplementary Table S2). Nakamura et al. (1999) divided B. subtilis into B. subtilis subsp. subtilis and Bacillus subtilis subsp. spizizenii mainly using DNA-DNA reassociation data. DNA-DNA relatedness $(67 \%)$ and $16 \mathrm{~S}$ rRNA gene sequence similarity $(99.8 \%)$ indicated that these two taxa are closely related; however, the gyrB gene sequence can be used to discriminate between them ( $95 \%$ sequence similarity). Pairwise analyses indicated that gyrB gene sequences (75.4$95.0 \%$ similarity) are more discriminatory than $16 \mathrm{~S}$ rRNA gene sequences (98.1-99.8\% similarity) for species differentiation. The gyrB gene sequence-based phylogenetic analysis was consistent with DNA-DNA reassociation data and a linear correlation was observed between $\operatorname{gyr} B$ gene sequence similarities and levels of DNA-DNA relatedness (Fig. 2). All strains that exhibited 95.5-100\% gyrB gene sequence similarity showed high DNA-DNA relatedness (70-100\%), suggesting that these strains are conspecific. Strains with approximately $95 \%$ or higher gyrB gene sequence similarity in the cluster exhibited DNA-DNA relatedness of $>70 \%$, an acceptable value for proposal of a single species. Strains with 93-95\% gyrB gene sequence similarity exhibited DNA-DNA relatedness of $60-70 \%$ without exception, indicating that they are grouped at the subspecies level. Exceptionally, B. subtilis subsp. spizizenii BCRC $17366^{\mathrm{T}}$ and B. vallismortis BCRC $17183^{\mathrm{T}}$ showed 93.9\% gyrB gene sequence similarity and $52 \%$ DNA-DNA relatedness. This finding indicated that it might be necessary to use several gene sequences and DNA-DNA hybridization to discriminate species relationships. Nevertheless, based on data obtained from the present study, the gyrB gene sequences have been shown to be a more efficient phylogenetic tool than the 16S RNA gene sequences for discriminating between species of this group.

In conclusion, the $16 \mathrm{~S}$ rRNA gene sequence is extremely limiting in the discrimination of species in the B. subtilis 


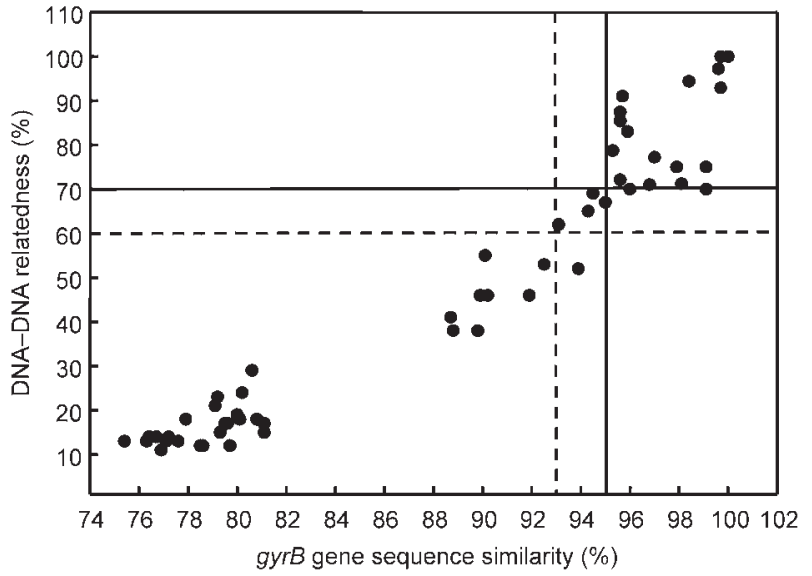

Fig. 2. Correlation between gyrB gene sequence similarity and DNA-DNA relatedness of Bacillus strains used in this study. Solid lines represent $70 \%$ DNA-DNA relatedness and $95 \%$ gyrB gene sequence similarity; dashed lines represent $60 \%$ DNA-DNA relatedness and $93 \%$ gyrB gene sequence similarity.

group. It is suggested that the $\operatorname{gyr} B$ gene may be a useful alternative to DNA-DNA hybridization for the identification and phylogenetic analysis of members of the B. subtilis group at the species and subspecies level, with some exceptions.

\section{Acknowledgements}

We thank T. Y. Liu, C. C. Liao and G. F. Yuan (Food Industry Research and Development Institute, Taiwan) for their encouragement. This research was supported by the Taiwanese Ministry of Economic Affairs (project no. 95-EC-17 A-17-R7-0525).

\section{References}

Ash, C., Farrow, J. A., Dorsch, M., Stackebrandt, E. \& Collins, M. D. (1991). Comparative analysis of Bacillus anthracis, Bacillus cereus, and related species on the basis of reverse transcriptase sequencing of $16 \mathrm{~S}$ rRNA. Int J Syst Bacteriol 41, 343-346.

Chelo, I. M., Zé-Zé, L. \& Tenreiro, R. (2007). Congruence of evolutionary relationships inside the Leuconostoc-Oenococcus-Weissella clade assessed by phylogenetic analysis of the 16S rRNA gene, dnaA, gyrB, rpoC and dnaK. Int J Syst Evol Microbiol 57, 276-286.

Chern, L.-L., Stackebrandt, E., Lee, S.-F., Lee, F.-L., Chen, J.-K. \& Fu, H.-M. (2004). Chitinibacter tainanensis gen. nov., sp. nov., a chitindegrading aerobe from soil in Taiwan. Int J Syst Evol Microbiol 54, 1387-1391.

Christensen, H., Nordentoft, S. \& Olsen, J. E. (1998). Phylogenetic relationships of Salmonella based on rRNA sequences. Int J Syst Bacteriol 48, 605-610.

Chun, J. \& Bae, K. S. (2000). Phylogenetic analysis of Bacillus subtilis and related taxa based on partial gyrA gene sequences. Antonie Van Leeuwenhoek 78, 123-127.

Ezaki, T., Hashimoto, Y. \& Yabuuchi, E. (1989). Fluorometric deoxyribonucleic acid-deoxyribonucleic acid hybridization in microdilution wells as an alternative to membrane filter hybridization in which radioisotopes are used to determine genetic relatedness among bacterial strains. Int J Syst Bacteriol 39, 224-229.

Felsenstein, J. (1993). PHYLIP (phylogeny inference package), version 3.5c. Distributed by the author. Department of Genetics, University of Washington, Seattle, USA.

Fitch, W. M. (1971). Toward defining the course of evolution: minimum change for a specific tree topology. Syst Zool 20, 406-416.

Fukushima, M., Kakinuma, K. \& Kawaguchi, R. (2002). Phylogenetic analysis of Salmonella, Shigella, and Escherichia coli strains on the basis of the gyrB gene sequence. J Clin Microbiol 40, 2779-2785.

Huang, W. M. (1996). Bacterial diversity based on type II DNA topoisomerase genes. Annu Rev Genet 30, 79-107.

Joung, K. B. \& Cote, J. C. (2002). Evaluation of ribosomal RNA gene restriction patterns for the classification of Bacillus species and related genera. J Appl Microbiol 92, 97-108.

Kasai, H., Ezaki, T. \& Harayama, S. (2000). Differentiation of phylogenetically related slowly growing mycobacteria by their gyrB sequences. J Clin Microbiol 38, 301-308.

Kimura, M. (1980). A simple method for estimating evolutionary rates of base substitutions through comparative studies of nucleotide sequences. J Mol Evol 16, 111-120.

Ko, K. S., Kim, J. W., Kim, J. M., Kim, W., Chung, S. I., Kim, I. J. \& Kook, Y. H. (2004). Population structure of the Bacillus cereus group as determined by sequence analysis of six housekeeping genes and the plcR gene. Infect Immun 72, 5253-5261.

Kumar, S., Tamura, K. \& Nei, M. (2004). MEGA3: integrated software for molecular evolutionary genetics analysis and sequence alignment. Brief Bioinform 5, 150-163.

La Duc, M. T., Satomi, M., Agata, N. \& Venkateswaran, K. (2004). gyrB as a phylogenetic discriminator for members of the Bacillus anthraciscereus-thuringiensis group. J Microbiol Methods 56, 383-394.

Martínez-Murcia, A. J., Benlloch, S. \& Collins, M. D. (1992). Phylogenetic interrelationships of members of the genera Aeromonas and Plesiomonas as determined by $16 \mathrm{~S}$ ribosomal DNA sequencing: lack of congruence with results of DNA-DNA hybridization. Int J Syst Bacteriol 42, 412-421.

Nakamura, L. K. (1989). Taxonomic relationship of black-pigmented Bacillus subtilis strains and a proposal for Bacillus atrophaeus sp. nov. Int J Syst Bacteriol 39, 295-300.

Nakamura, L. K., Roberts, M. S. \& Cohan, F. M. (1999). Relationship of Bacillus subtilis clades associated with strains 168 and W23: a proposal for Bacillus subtilis subsp. subtilis subsp. nov. and Bacillus subtilis subsp. spizizenii subsp. nov. Int J Syst Bacteriol 49, 1211-1215.

Niemann, S., Harmsen, D., Rusch-Gerdes, S. \& Richter, E. (2000). Differentiation of clinical Mycobacterium tuberculosis complex isolates by gyrB DNA sequence polymorphism analysis. J Clin Microbiol 38, 3231-3234.

Palmisano, M. M., Nakamura, L. K., Duncan, K. E., Istock, C. A. \& Cohan, F. M. (2001). Bacillus sonorensis sp. nov., a close relative of Bacillus licheniformis, isolated from soil in the Sonoran Desert, Arizona. Int J Syst Evol Microbiol 51, 1671-1679.

Priest, F. G., Goodfellow, M., Shute, L. A. \& Berkeley, R. C. W. (1987). Bacillus amyloliquefaciens sp. nov., nom. rev. Int J Syst Bacteriol 37, 69-71.

Roberts, M. S., Nakamura, L. K. \& Cohan, F. M. (1994). Bacillus mojavensis sp. nov., distinguishable from Bacillus subtilis by sexual isolation, divergence in DNA sequence, and differences in fatty acid composition. Int J Syst Bacteriol 44, 256-264.

Roberts, M. S., Nakamura, L. K. \& Cohan, F. M. (1996). Bacillus vallismortis sp. nov., a close relative of Bacillus subtilis, isolated from soil in Death Valley, California. Int J Syst Bacteriol 46, 470-475. 
Saitou, N. \& Nei, M. (1987). The neighbor-joining method: a new method for reconstructing phylogenetic trees. Mol Biol Evol 4, 406-425.

Skerman, V. B. D., McGowan, V. \& Sneath, P. H. A. (editors) (1980). Approved lists of bacterial names. Int J Syst Bacteriol 30, 225-420.

Smith, N. R., Gibson, T., Gordon, R. E. \& Sneath, P. H. (1964). Type cultures and proposed neotype cultures of some species in the genus Bacillus. J Gen Microbiol 34, 269-272.

Stackebrandt, E., Frederiksen, W., Garrity, G. M., Grimont, P. A. D., Kämpfer, P., Maiden, M. C. J., Nesme, X., Rosselló-Mora, R., Swings, J. \& other authors (2002). Report of the ad hoc committee for the reevaluation of the species definition in bacteriology. Int J Syst Evol Microbiol 52, 1043-1047.

Tai, C. J., Kuo, H. P., Lee, F. L., Chen, H. K., Yokota, A. \& Lo, C. C. (2006). Chryseobacterium taiwanense sp. nov., isolated from soil in Taiwan. Int J Syst Evol Microbiol 56, 1771-1776.

Thompson, J. D., Gibson, T. J., Plewniak, F., Jeanmougin, F. \& Higgins, D. G. (1997). The CLUSTAL_X windows interface: flexible strategies for multiple sequence alignment aided by quality analysis tools. Nucleic Acids Res 25, 4876-4882.

Vandamme, P., Pot, B., Gillis, M., De Vos, P., Kersters, K. \& Swings, J. (1996). Polyphasic taxonomy, a consensus approach to bacterial systematics. Microbiol Rev 60, 407-438.

Watt, P. M. \& Hickson, I. D. (1994). Structure and function of type II DNA topoisomerases. Biochem J 303, 681-695.

Wayne, L. G., Brenner, D. J., Colwell, R. R., Grimont, P. A. D., Kandler, O., Krichevsky, M. I., Moore, L. H., Moore, W. E. C., Murray, R. G. E. \& other authors (1987). International Committee on Systematic Bacteriology. Report of the ad hoc committee on reconciliation of approaches to bacterial systematics. Int J Syst Bacteriol 37, 463-464.

Woese, C. R. (1987). Bacterial evolution. Microbiol Rev 51, 221-271. Yamamoto, S. \& Harayama, S. (1995). PCR amplification and direct sequencing of $g y r B$ genes with universal primers and their application to the detection and taxonomic analysis of Pseudomonas putida strains. Appl Environ Microbiol 61, 1104-1109.

Yamamoto, S. \& Harayama, S. (1996). Phylogenetic analysis of Acinetobacter strains based on the nucleotide sequences of $\operatorname{gr} B$ genes and on the amino acid sequences of their products. Int J Syst Bacteriol 46, 506-511.

Yamamoto, S. \& Harayama, S. (1998). Phylogenetic relationships of Pseudomonas putida strains deduced from the nucleotide sequences of gyrB, rpoD and $16 \mathrm{~S}$ rRNA genes. Int $J$ Syst Bacteriol 48, 813-819.

Yamamoto, S., Bouvet, P. J. \& Harayama, S. (1999). Phylogenetic structures of the genus Acinetobacter based on $\operatorname{gyrB}$ sequences: comparison with the grouping by DNA-DNA hybridization. Int J Syst Bacteriol 49, 87-95.

Yáñez, M. A., Catalán, V., Apráiz, D., Figueras, M. J. \& MartínezMurcia, A. J. (2003). Phylogenetic analysis of members of the genus Aeromonas based on gyrB gene sequences. Int J Syst Evol Microbiol 53, 875-883.

Zeigler, D. R. (2003). Gene sequences useful for predicting relatedness of whole genomes in bacteria. Int J Syst Evol Microbiol 53, 1893-1900. 